\title{
MEASUREMENT OF THE VOLUME OF GAS IN THE GASTRO- INTESTINAL TRACT. VALUES IN NORMAL SUBJECTS AND AMBULATORY PATIENTS ${ }^{1}$
}

\author{
By GEORGE N. BEDEll,2 ROBERT MARShall, ${ }^{3}$ ARTHUR B. DuBOIS, ANd \\ JOHN H. HARRIS
(From the Department of Physiology and Pharmacology, Graduate School of Medicine, Uni- zersity of Pennsylvania, and the Department of Radiology, Hospital of the University of Pennsylvania, Philadelphia, Penna.)

(Submitted for publication October 5, 1955 ; accepted November 16, 1955)

During the course of lung volume studies it became necessary to determine the effect of gases in the abdomen on the thoracic gas volume as measured by a plethysmographic method. Blair, Dern, and Bates (1), using a plethysmographic method for the determination of abdominal gas volume, reported that the average volume of gas present in the gastro-intestinal tract was approximately one liter. No other studies have been reported either to confirm or to contradict these results and the purpose of this paper is to describe an improved plethysmographic method for the determination of abdominal gas volume and to report the results obtained in normal subjects and in ambulatory patients with pulmonary disease. The average volume of abdominal gas is of interest as it relates to gastroenterology, decompression and measurement of the specific gravity of the body.

The principle upon which the plethysmographic method is based is that the volume of a gas in a closed space in the body varies in inverse proportion to its pressure provided that the temperature remains constant (Boyle's law). If the pressure change in a volume of gas is small in relation to the initial pressure then the initial volume $\mathrm{V}$ can be calculated from the equation:

$$
\mathrm{V}=\frac{\Delta \mathrm{VP}}{\Delta \mathrm{P}}
$$

where $\mathrm{P}$ is the initial pressure and $\Delta \mathrm{P}$ and $\Delta \mathrm{V}$ are the induced changes of pressure and volume, respectively (2). This equation has been applied to

1 These studies were aided (in part) by a contract between the Office of Naval Research, Department of the Navy, and the University of Pennsylvania, NR112-323.

2 Present Address: Department of Internal Medicine, University Hospital of State University of Iowa, Iowa City, Ia.

3 Present Address: Dunn Laboratories, St. Bartholomew's Hospital, London, England. the measurement of abdominal gas volume. The initial pressure is usually a few centimeters of water above atmospheric pressure but the difference is so small in relation to atmospheric pressure that it may be neglected. The change of pressure in the abdomen resulting from voluntary straining is measured by means of an intragastric balloon and changes of pressure in the stomach are considered to be representative of changes in pressure throughout the abdominal cavity. This is an assumption subject to proof but if it is true, volumes of gas introduced into the colon or small bowel should be measured as accurately by recording of intragastric pressure as volumes of gas introduced directly into the stomach. The change in volume of the abdominal gas is measured by use of the body plethysmograph.

The first objective in these studies was to determine the degree of reproducibility and accuracy of measurement of volumes of gas introduced into the stomach. Secondly, it was necessary to establish whether the method could measure accurately volumes of gas introduced into the colon. If this were possible then the theory that the abdominal cavity acts as a unit, with pressures generated by contraction of the abdominal muscles and diaphragm equally transmitted to all parts, would be substantiated. Thirdly, the volume of gas normally present in the gastro-intestinal tract was measured.

\section{METHOD}

The apparatus used is shown diagrammatically in Figure 1 . The body plethysmograph, $\mathrm{B}$, which has been described previously $(2,3)$ is a chamber of about 600 liters' capacity and having an airtight door. The pressure differential between the chamber and the atmosphere is measured by a sensitive differential capacitance manometer $\mathrm{C}$, the output from which is made to record on the $\mathrm{X}$ axis of a cathode ray oscilloscope $\mathrm{O}$. The sensitivity 
of the manometer and the amplification of the output are such that a pressure change of $0.025 \mathrm{~cm} . \mathrm{H}_{2} \mathrm{O}$ in the plethysmograph produces a deflection of 1 inch on the $\mathrm{X}$ axis of the oscilloscope. The pressure changes in the closed plethysmograph are proportional to volume changes of the air in the plethysmograph and the manometer is calibrated directly in terms of volume change by recording the deflection produced on the oscilloscope when a known volume of air is introduced into, and withdrawn from, the plethysmograph by a diaphragm pump of 30 ml. stroke volume. The calibration is carried out when the subject is in the plethysmograph.

The pressure in the stomach is measured by use of an intragastric balloon of the type used for intra-esophageal pressure measurements. This is a thin latex balloon, approximately $10 \mathrm{~cm}$. long and $1 \mathrm{~cm}$. wide, attached to a length of $1 \mathrm{~mm}$. bore polyethylene tube. The tube is connected to a capacitance manometer, $P$, outside the plethysmograph and the output from this manometer is recorded on the $\mathrm{Y}$ axis of the oscilloscope. The sensitivity of this manometer is such that $5 \mathrm{~cm} . \mathrm{H}_{2} \mathrm{O}$ produces a deflection of 1 inch on the oscilloscope. It is calibrated against a water manometer.

The procedure for measurement of the abdominal gas volume is as follows. The balloon is passed through the nose and swallowed until the tip is about $60 \mathrm{~cm}$. from the nares. The location of the balloon in the stomach can be verified by observing the pressure in the balloon when the subject sniffs. This maneuver momentarily increases the pressure in the abdomen and lowers the pressure in the thorax.

The subject is seated in the plethysmograph and approximately $2 \mathrm{ml}$. of air are introduced into the intragastric balloon. About 2 minutes must be allowed between closing the plethysmograph and making the measurements of abdominal gas so that the temperature and humidity in the plethysmograph may become stabilized. The plethysmograph is opened periodically to the atmosphere through a solenoid operated vent so that the pressure remains approximately atmospheric.

The subject is instructed to stop breathing at the end of a normal expiration but to keep his airways open. $\mathrm{He}$ is then instructed to tense the abdominal muscles by "pushing out against the belt," or against the hands placed firmly on the abdomen, in rapid repeated movements. This maneuver is directed towards increasing the pressure in the abdomen without changing the pressure of the air in the thorax. The tracing obtained on the oscilloscope screen is a sloping straight line repeated with each increase of abdominal pressure (Figures $2 a$ and $b$ ). This tracing may be recorded either by use of an Oscillotracer 4 or by photographing it, using a still camera with a bulb exposure.

\section{CALCULATION}

If the equation shown above is applied to the measurement of abdominal gas volume, then the initial volume

4 R. A. Waters, Inc., Waltham, Mass.

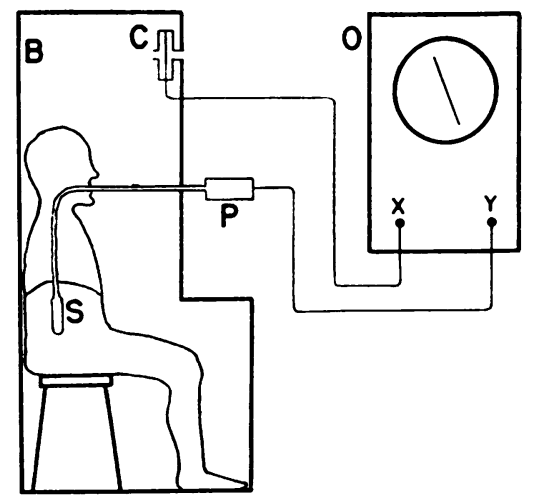

Fig. 1. Diagram of the Apparatus

$\mathrm{B}$, body plethysmograph; $\mathrm{C}$, pressure gauge; $\mathrm{P}$, pressure gauge; $\mathrm{S}$, intragastric balloon; $\mathrm{O}$, cathode ray oscilloscope.

of abdominal gas, $\mathrm{V}$, is given by

$$
\mathrm{V}=\frac{\Delta \mathrm{V} 970}{\Delta \mathrm{P}} \mathrm{ml} \text {. }
$$

$970\left(\mathrm{~cm} . \mathrm{H}_{2} \mathrm{O}\right)$ is atmospheric pressure minus the pressure of water vapor at $37^{\circ} \mathrm{C}$ since water vapor tension in the gastro-intestinal tract is presumed constant. The $\mathrm{Y}$ axis of the oscilloscope is calibrated in terms of pressure change in the stomach and the $\mathrm{X}$ axis is calibrated directly in terms of volume change in the plethysmograph. Thus the slope of the line traced on the oscilloscope is proportional to $\Delta \mathrm{P} / \Delta \mathrm{V}$ so that, adding the calibration factors, the above equation may be rewritten

$$
\mathrm{V}=\frac{970 \mathrm{Cv}}{\mathrm{Cp} \lambda} \mathrm{ml} \text {. }
$$

where $\mathrm{Cv}$ is the calibration of volume change in the plethysmograph expressed as $\mathrm{ml}$. per 1-inch deflection, $\mathrm{Cp}$ is the calibration of pressure change expressed as $\mathrm{cm}$. $\mathrm{H}_{2} \mathrm{O}$ per 1 -inch deflection and $\lambda$ is the slope of the oscilloscope tracing.

Unsatisfactory tracings may be produced in two ways, either by closure of the glottis or by production of airflow. In either case the use of a flowmeter aids in the detection of the artefact. If the subject closes the glottis, then the thoracic gas is also compressed during the maneuver for compression of abdominal gas. When this happens the slope of the tracing is much greater (see Figure 2c) since a very much larger volume of gas is being compressed, and also the cardiac fluctuations usually seen on the flowmeter disappear when the glottis is closed. Unsatisfactory tracings may be obtained if the subject inspires or expires during the maneuver. If the subject inspires as the abdomen is compressed the alveolar pressure is lowered and the inspired air is expanded as it is warmed and humidified. Both of these effects will tend to increase the pressure in the plethysmograph (whereas compression of abdominal gas decreases the pressure in the plethysmograph) and a falsely low value for abdominal gas volume will be obtained. A falsely high value 

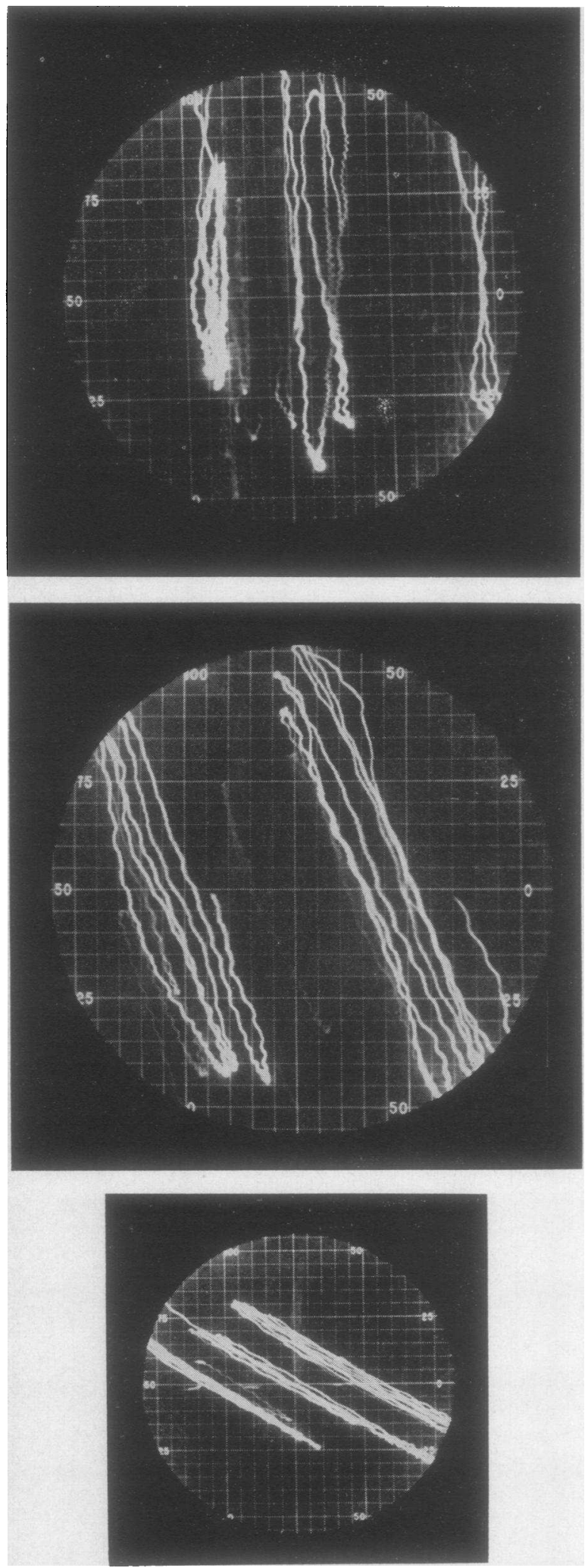

FIG. 2. will be obtained if the subject expires. In either case the flowmeter tracing will show evidence of airflow.

Even after practice, some subjects are unable to produce satisfactory tracings and the results in 7 out of 67 subjects in this series had to be discarded for this reason. A mechanically driven belt, designed alternately to compress and release the abdomen, was tried in efforts to make the method less dependent on the subject's cooperation but the device proved unsatisfactory due to some slight compression of lung gas.

Measurement of gas volumes added to the stomach. Two polyethelene tubes, one with balloon attached, the other open, were tied together and passed into the stomach. The volume of gas present in the abdomen was determined by the plethysmograph method. This figure was used as a control reading. Increments of $200 \mathrm{ml}$. were then added through the second tube by means of a syringe. The volume of abdominal gas was measured after each increment. Radiographs of the abdomen were taken before the addition of air and after the introduction of 500 $\mathrm{ml}$. of air into the stomach.

Measurement of gas volumes added to the colon. The stomach balloon was placed as previously described. A rectal catheter was used to inject gas into the colon. This catheter is of the type used to administer barium enemas. It has an inflatable balloon of $30-\mathrm{ml}$. volume near the tip to prevent its escape from the rectum. The balloon also helped to prevent escape of gas from the colon. Control measurements were made and then air was added to the colon in increments of $300 \mathrm{ml}$. The volume of abdominal gas was measured after each increment by the same technique of measuring changes in intragastric pressure and plethysmographic volume during contraction of the abdominal muscles. While introducing gas into the colon in subjects R. M. and A. B. D. B. the pressure in the colon was recorded between cramps with an aneroid manometer before and after the introduction of each volume of gas and the circumference of the abdomen was measured by a tape placed at the level of the umbilicus. Radiographs of the abdomen were taken before the addition of air and after the introduction of 600 and $1,200 \mathrm{ml}$. of air into the colon.

\section{RESULTS}

\section{1) Accuracy of measuring volumes of gas in the stomach}

A total of 38 gas volumes were introduced into the stomach in the two subjects. Figure 3 is a

Fig. 2. Photographs of the Oscilloscope Trace with Intragastric Pressure Recorded on the Y Axis and Plethysmographic Pressure on the X Axis

A : Control showing little or no gas; B : After the addition of $1,200 \mathrm{ml}$. of air to the colon; C: Tracing of mouth pressure ( $\mathrm{Y}$ axis) and plethysmographic pressure ( $\mathrm{X}$ axis) with subject panting against a closed shutter. Shown to demonstrate the slope of the tracing when lung gas is compressed. 


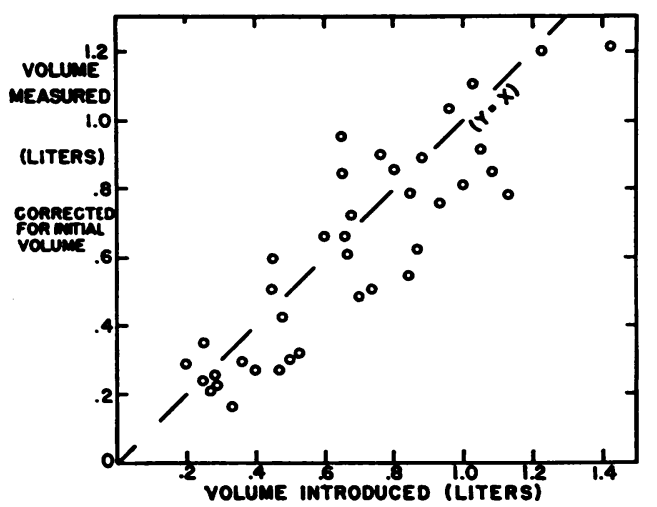

Fig. 3. Graphs Showing the Relationship BeTWEen the Volume of Gas INTROduced INTO THE Stomach and the Increase in Abdominal Gas Volume as Measured by the Plethysmographic Method

Thirty-eight measurements in subjects $R$. $M$. and A. B. D. B.

scatter diagram of these data. The volume introduced is on the abscissa, and measured volume minus the initial control volume is plotted on the ordinate. It can be seen that the grouped data are sufficiently linear to warrant application of a linear regression equation to the data of individual experiments (Figures 4 and 5).

Figure 4 shows this plot from an experiment in which stomach gas was introduced into the subject

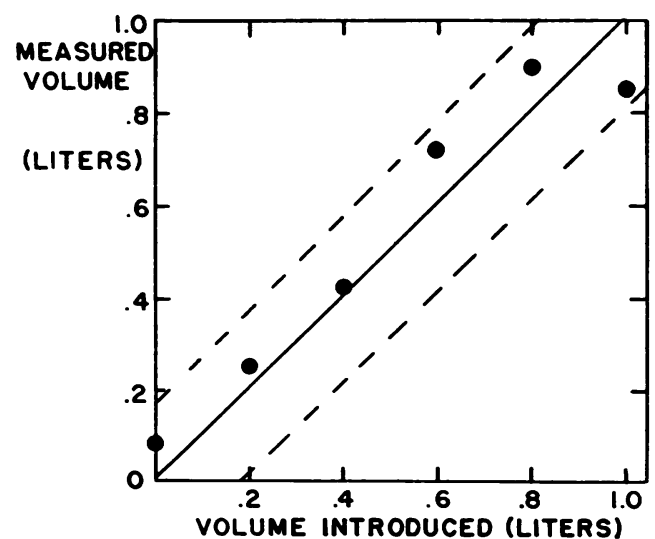

Fig. 4. Graph Showing the Relationship between the Volume of Gas Introduced into the Stomach and the Increase in Abdominal Gas Volume as MeasURED BY THE PlethySMOgRAPHIC METhOD

Results of 1 experiment on subject R. M. Dashed lines represent two times the standard error of estimation.
R. M. The measured initial volume is $84 \mathrm{ml}$., the $\mathrm{Y}$ intercept is $6 \mathrm{ml}$. The slope of the line of regression is 1.0. The standard error of estimate is $91 \mathrm{ml}$.

Figure 5 shows a similar plot from an experiment in which stomach gas was introduced into subject A. B. D. B. The measured initial volume is $48 \mathrm{ml}$., the $\mathrm{Y}$ intercept is $32 \mathrm{ml}$. The slope of the line of regression is 1.43 . The standard error of estimate is $67 \mathrm{ml}$.

The radiograph of the stomach after the injection of $500 \mathrm{ml}$. of air (Figure 8) shows that this volume is many times that usually present in the stomach and that it produces considerable gastric distension.

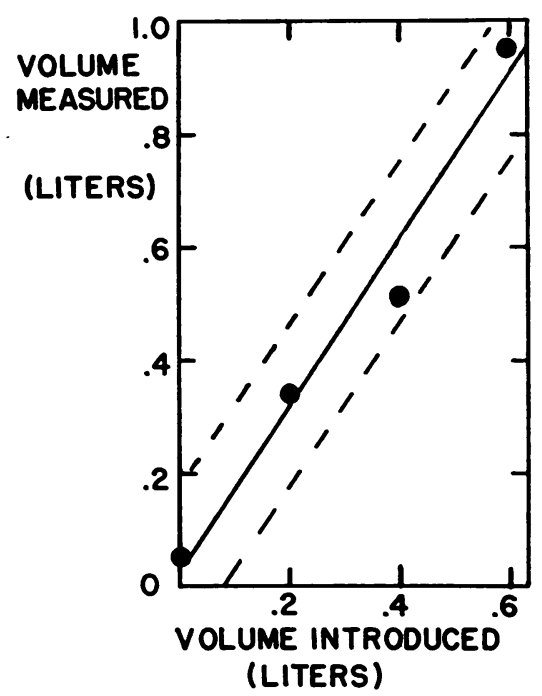

Fig. 5. Graph Showing the Relationship between the Volume of Gas Introduced into the Stomach and the InCrease in Abdominal Gas Volume as Measured by the Plethysmographic Method

Results of 1 experiment on subject A. B. D. B.

2) Accuracy of measuring volumes of gas in the colon

A total of 9 gas volumes were introduced into the colon in the same two subjects.

To determine the accuracy of the method, a statistical analysis of the two colon gas experiments was undertaken as it was for the stomach gas experiments.

Figure 6 shows this plot from an experiment in which gas was introduced into the colon of subject $R$. M. The measured initial volume is $0 \mathrm{ml}$. 


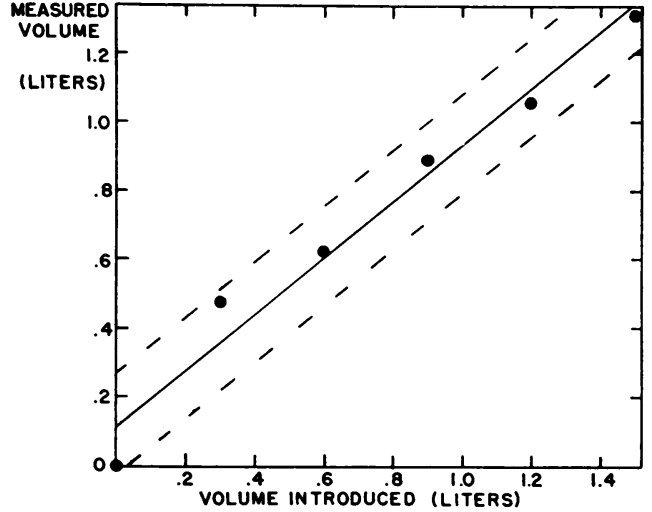

Fig. 6. Graph Showing the Relationship between the Volume of Gas Introduced into the Colon and the Increase in Abdominal Gas Volume as MeasURed by the Plethysmographic Method

Results of one experiment on subject R. M.

The $\mathrm{Y}$ intercept is $112 \mathrm{ml}$. The slope of the line of regression is 0.817 . The standard error of estimate is $70 \mathrm{ml}$.

Figure 7 shows a similar plot from an experiment in which colon gas was introduced into subject A.B.D.B. The measured initial volume is $69 \mathrm{ml}$., the $\mathrm{Y}$ intercept is $106 \mathrm{ml}$. The slope of the line of regression is 0.90 . The standard error of estimate is $60 \mathrm{ml}$. We conclude from this experiment that with straining, increments of pressure are equally transmitted throughout the abdominal cavity. Although the slope of the regres-

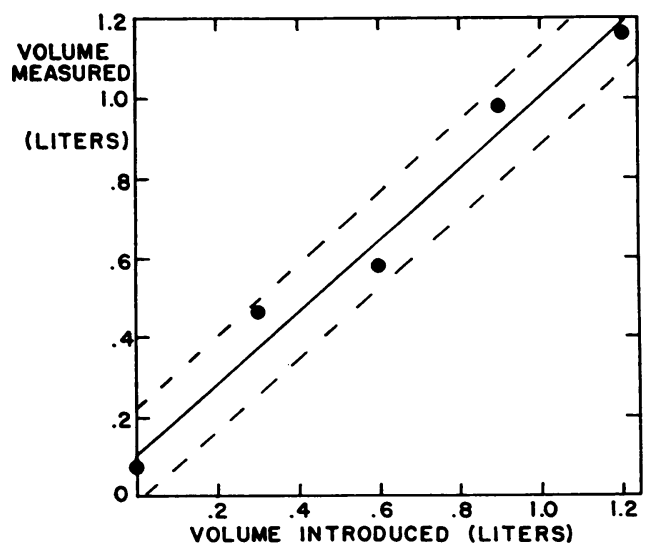

Fig. 7. Graph Showing the Relationship between the Volume of Gas Introduced into the Colon and the Increase in Abdominal Gas Volume as Measured by the Plethysmographic Method

Results of one experiment on subject A. B. D. B.
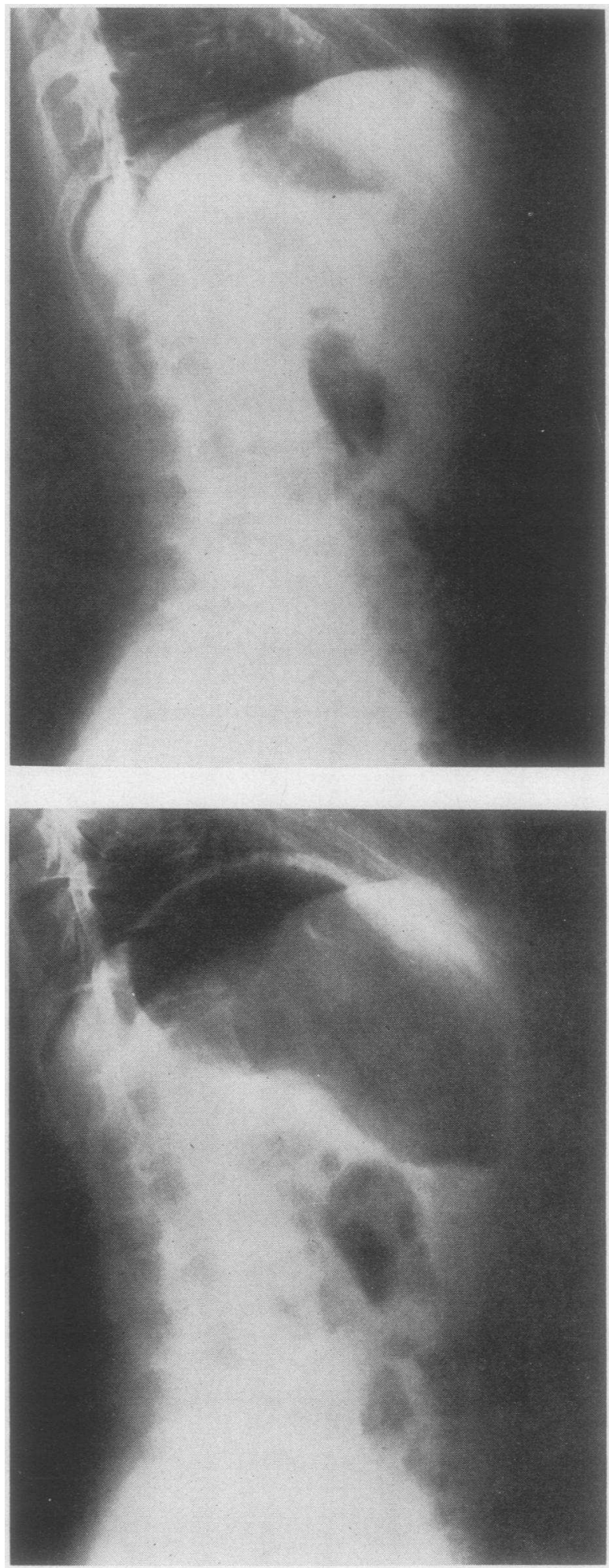

Fig. 8. Radiographs of the Abdomex (a) Control, (b) After INjection of 500 ML. OF Air isto the Stomach (Sibject R. M., 2/17/55) 
TABLE I

Some effects of injecting gas into the colon

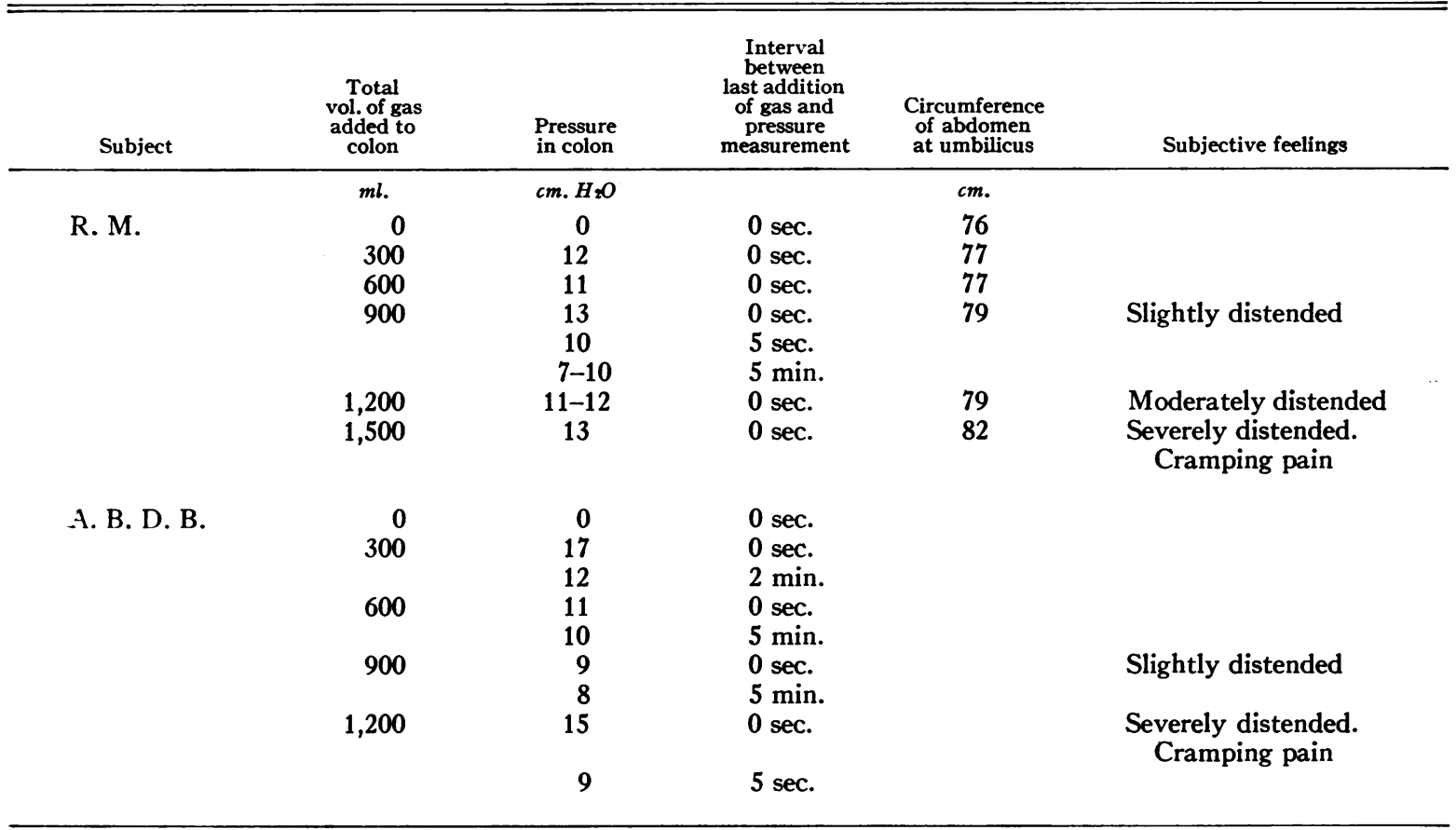

sion lines should ideally be 1.00 , the deviation of individual points from the regression line was sufficiently great so that they could conceivably have represented a line of slope 1.0. There is, however, doubt about the second decimal place.

The subjects noted that when the rectum became distended there would be pain, which was relieved when the gas bubbled up into the more proximal regions of the colon. A volume of $300 \mathrm{ml}$. introduced into the rectum brought the rectal pressure to about $10 \mathrm{~cm} . \mathrm{H}_{2} \mathrm{O}$ (Table I). Further introduction of gas caused transient rises in pressure which diminished to about $10 \mathrm{~cm} . \mathrm{H}_{2} \mathrm{O}$ after some of the gas escaped to other parts of the bowel. By the time that $1,200 \mathrm{ml}$. had been introduced, the pressure was still in the range of $10 \mathrm{~cm} . \mathrm{H}_{2} \mathrm{O}$. At this point the subjects felt distended with gas and there was mild cramping pain. In R. M. a final volume of $1,500 \mathrm{ml}$. was reached at which point the rectal pressure was $13 \mathrm{~cm} . \mathrm{H}_{2} \mathrm{O}$. It is apparent from the X-ray films (Figure 9) that the abdomen which contained $1,200 \mathrm{ml}$. of added gas was moderately to markedly distended by comparison with the control film.

\section{3) Volume of abdominal gas in normal subjects and in patients with pulmonary disease}

For this series of experiments, two groups of people were studied: (A) normal subjects and (B) patients with pulmonary disease. The studies were done at any time of the day, with no special preparation.

The patients with pulmonary disease were undergoing studies of compliance and airway resistance which necessitated placing a balloon in the esophagus. The balloon was passed first into the stomach, abdominal gas was measured, and then the balloon was withdrawn into the esophagus for the remainder of the studies.

(A) Normal subjects. A total of 32 observations is reported in 13 normal subjects, 11 men and two women; their age range was 20 to 43 years (Table II-A). There are multiple determinations on different days in several subjects. The average amount of abdominal gas in these subjects was $115 \mathrm{ml}$. ( $\mathrm{SD}= \pm 127 \mathrm{ml} ., \mathrm{SE}= \pm 23 \mathrm{ml}$.).

(B) Patients with lung disease. Forty-eight determinations of abdominal gas are reported from 
47 patients with lung disease (Table II-B). One patient had two observations on different days. The patients consist of 35 men and 12 women and range in age between 15 and 76 years. The average amount of abdominal gas in these patients was $116 \mathrm{ml}$. ( $\mathrm{SD}= \pm 125 \mathrm{ml} ., \mathrm{SE}= \pm 18 \mathrm{ml}$.).

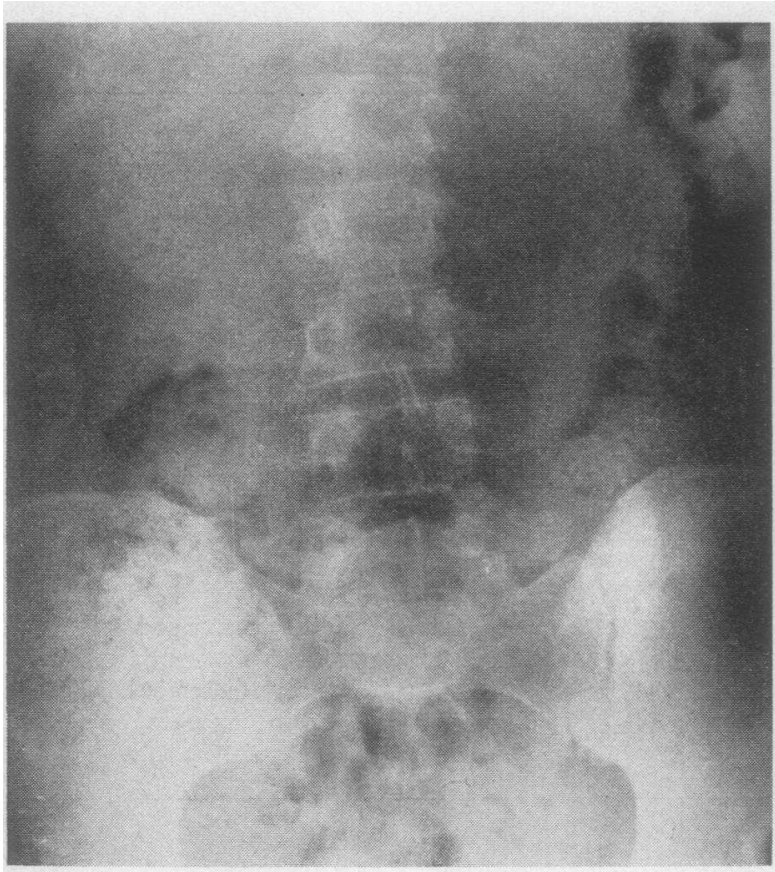

(a)

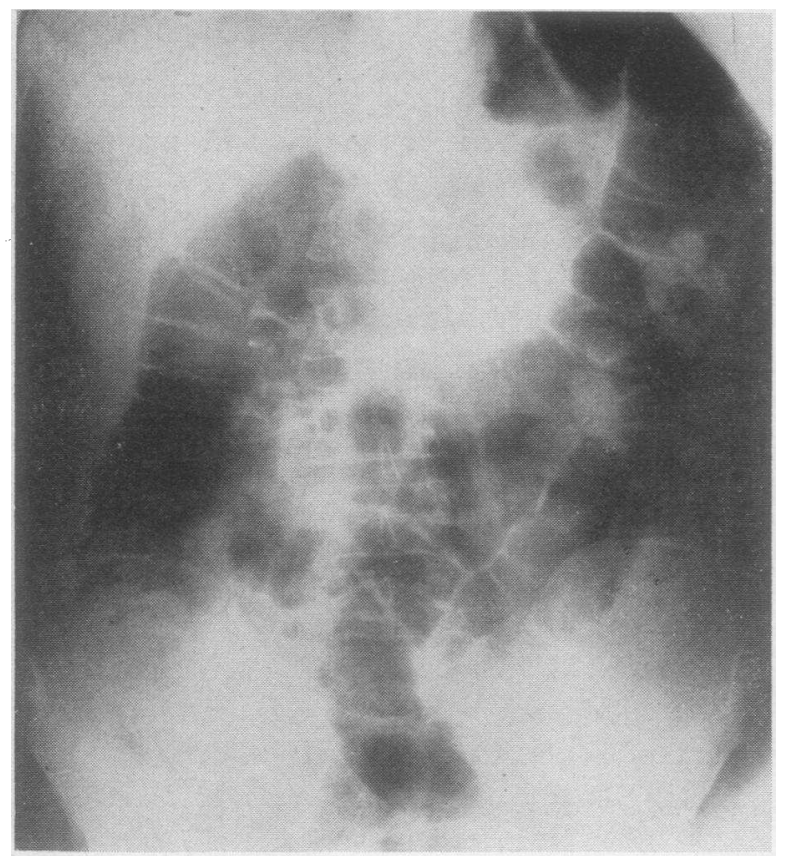

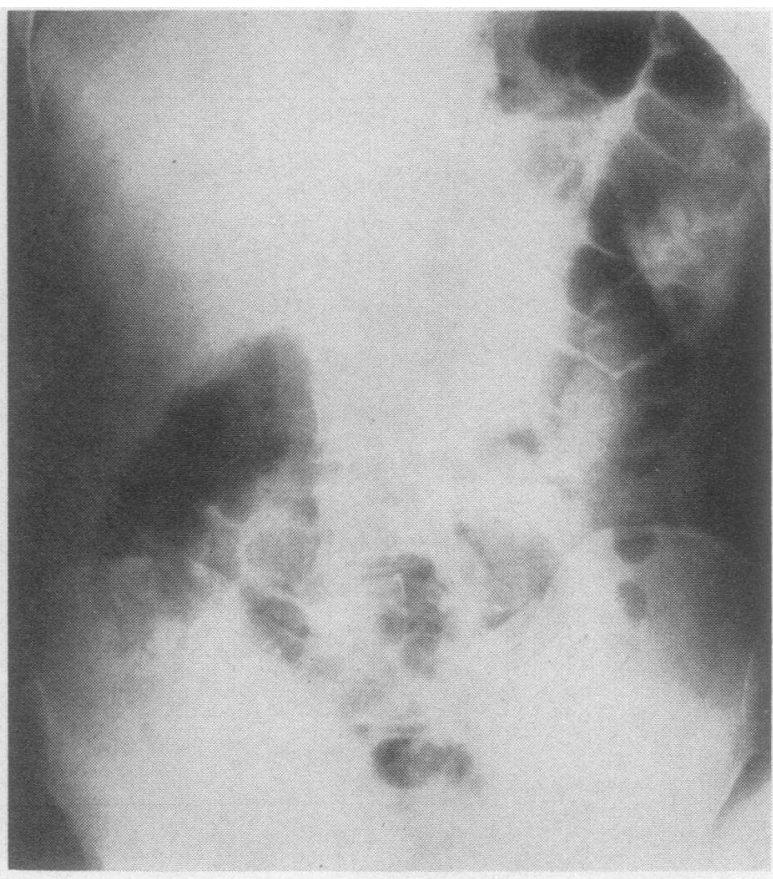

(b)

Fig. 9. Radiographs of the Abdomen (a) Control, (b) After Injection of 600 ml. of Air into the Colon, (c) After Injection of 1,200 ML. OF Air into the Colon, Compare with Figure 6 
TABLE II A

A) The volume of abciominal gas in normal subjects

\begin{tabular}{|c|c|c|c|c|c|c|c|c|c|}
\hline Subject & Sex & Age & Date & $\begin{array}{c}\text { Volume of } \\
\text { abdominal } \\
\text { gas }\end{array}$ & Subject & Sex & Age & Date & $\begin{array}{c}\text { Volume of } \\
\text { abdominal } \\
\text { gas }\end{array}$ \\
\hline $\begin{array}{l}\text { R. M. } \\
\text { R. M. } \\
\text { R. M. } \\
\text { R. M. } \\
\text { R. M. } \\
\text { R. M. } \\
\text { R. M. } \\
\text { R. M. } \\
\text { R. M. } \\
\text { R. M. } \\
\text { R. M. } \\
\text { A. B. D. B. } \\
\text { A. B. D. B. } \\
\text { A. B. D. B. } \\
\text { A. B. D. B. } \\
\text { A. B. D. B. }\end{array}$ & $\mathbf{M}$ & 32 & $\begin{array}{l}11 / 12 / 54 \\
12 / 22 / 54 \\
1 / 13 / 55 \\
1 / 19 / 55 \\
1 / 28 / 55 \\
2 / 3 / 55 \\
2 / 4 / 55 \\
2 / 7 / 55 \\
2 / 10 / 55 \\
2 / 17 / 55 \\
3 / 31 / 55 \\
11 / 12 / 54 \\
11 / 18 / 54 \\
12 / 7 / 54 \\
1 / 17 / 55 \\
1 / 18 / 55\end{array}$ & $\begin{array}{r}m l . \\
34 \\
63 \\
182 \\
67 \\
261 \\
84 \\
132 \\
106 \\
55 \\
158 \\
0 \\
110 \\
0 \\
0 \\
0 \\
0\end{array}$ & $\begin{array}{l}\text { A. B. D. B. } \\
\text { A. B. D. B. } \\
\text { G. B. } \\
\text { G. B. } \\
\text { G. B. } \\
\text { R. S. M. } \\
\text { R. S. M. } \\
\text { E. L. } \\
\text { M. R. } \\
\text { P. C. } \\
\text { J. M. } \\
\text { E. R. } \\
\text { D. G. } \\
\text { E. P. } \\
\text { E. H. } \\
\text { K. S. }\end{array}$ & $\begin{array}{l}\mathbf{M} \\
\mathbf{M} \\
\mathbf{F} \\
\mathbf{M} \\
\mathbf{M} \\
\mathbf{F} \\
\mathbf{M} \\
\mathbf{M} \\
\mathbf{M} \\
\mathbf{M} \\
\mathbf{M} \\
\mathbf{M}\end{array}$ & $\begin{array}{l}32 \\
33 \\
\\
\\
20 \\
\\
32 \\
34 \\
22 \\
30 \\
35 \\
43 \\
20 \\
34 \\
35\end{array}$ & $\begin{array}{l}3 / 4 / 55 \\
5 / 17 / 55 \\
12 / 22 / 54 \\
12 / 21 / 54 \\
3 / 17 / 55 \\
1 / 25 / 55 \\
2 / 9 / 55\end{array}$ & $\begin{array}{r}\boldsymbol{m l} . \\
48 \\
59 \\
0 \\
84 \\
53 \\
0 \\
272 \\
70 \\
240 \\
100 \\
270 \\
456 \\
0 \\
102 \\
506 \\
179\end{array}$ \\
\hline
\end{tabular}

Mean volume of abdominal gas $=115 \mathrm{ml}$.

$\mathrm{SD}= \pm 127 \mathrm{ml}$.

$\mathrm{SE}= \pm 23 \mathrm{ml}$.

TABLE II B

B) The volume of abdominal gas in ambulatory patients

\begin{tabular}{|c|c|c|c|c|c|c|c|c|}
\hline Subject & Sex & Age & Date & $\begin{array}{c}\text { Volume of } \\
\text { abdominal } \\
\text { gaas }\end{array}$ & Subject & Sex & Age & $\begin{array}{c}\text { Volume of } \\
\text { abdominal } \\
\text { gas }\end{array}$ \\
\hline $\begin{array}{l}\text { R.C. } \\
\text { E. B. } \\
\text { O. L. } \\
\text { O. L. } \\
\text { L. L. } \\
\text { R.D. } \\
\text { M.H. } \\
\text { C.S. } \\
\text { M.M. } \\
\text { S. Z. } \\
\text { W.E. } \\
\text { R.G. } \\
\text { J.L. } \\
\text { B. J. } \\
\text { J. W. } \\
\text { C. K. } \\
\text { A.V. } \\
\text { W. H. } \\
\text { B.S. } \\
\text { E. K. } \\
\text { L.W. } \\
\text { E. M. } \\
\text { H.G. } \\
\text { W. C. }\end{array}$ & $\begin{array}{l}\mathbf{M} \\
\mathbf{F} \\
\mathbf{M} \\
\mathbf{M} \\
\mathbf{F} \\
\mathbf{M} \\
\mathbf{F} \\
\mathbf{F} \\
\mathbf{F} \\
\mathbf{M} \\
\mathbf{M} \\
\mathbf{F} \\
\mathbf{M} \\
\mathbf{M} \\
\mathbf{M} \\
\mathbf{F} \\
\mathbf{M} \\
\mathbf{M} \\
\mathbf{F} \\
\mathbf{M} \\
\mathbf{F} \\
\mathbf{F} \\
\mathbf{M} \\
\mathbf{M}\end{array}$ & $\begin{array}{l}30 \\
17 \\
51 \\
51 \\
32 \\
45 \\
52 \\
46 \\
52 \\
21 \\
57 \\
45 \\
65 \\
28 \\
45 \\
47 \\
56 \\
54 \\
30 \\
63 \\
49 \\
49 \\
54 \\
36\end{array}$ & $\begin{array}{l}1 / 14 / 55 \\
2 / 3 / 55\end{array}$ & $\begin{array}{r}m l . \\
233 \\
375 \\
134 \\
0 \\
0 \\
92 \\
118 \\
13 \\
103 \\
137 \\
0 \\
56 \\
108 \\
0 \\
104 \\
00 \\
200 \\
128 \\
0 \\
537 \\
210 \\
0 \\
244 \\
330\end{array}$ & $\begin{array}{l}\text { E.P. } \\
\text { O. H. } \\
\text { J. K. } \\
\text { C. E. } \\
\text { H. W. } \\
\text { J. D. } \\
\text { J. H. } \\
\text { R.M. } \\
\text { G.D. } \\
\text { A. C. } \\
\text { E. Z. } \\
\text { W. M. } \\
\text { J. D. } \\
\text { J. W. } \\
\text { C.P. } \\
\text { H. B. } \\
\text { A.S. } \\
\text { A. C. } \\
\text { R.C. } \\
\text { L. H. } \\
\text { I. M. } \\
\text { J. W. } \\
\text { R. N. } \\
\text { R. W. }\end{array}$ & $\begin{array}{l}\mathbf{F} \\
\mathbf{M} \\
\mathbf{M} \\
\mathbf{M} \\
\mathbf{M} \\
\mathbf{M} \\
\mathbf{M} \\
\mathbf{M} \\
\mathbf{M} \\
\mathbf{M} \\
\mathbf{M} \\
\mathbf{M} \\
\mathbf{M} \\
\mathbf{M} \\
\mathbf{M} \\
\mathbf{M} \\
\mathbf{M} \\
\mathbf{M} \\
\mathbf{M} \\
\mathbf{M} \\
\mathbf{F} \\
\mathbf{M} \\
\mathbf{M} \\
\mathbf{M}\end{array}$ & $\begin{array}{l}56 \\
23 \\
31 \\
42 \\
52 \\
66 \\
30 \\
15 \\
47 \\
76 \\
16 \\
74 \\
57 \\
48 \\
64 \\
59 \\
53 \\
61 \\
55 \\
28 \\
44 \\
51 \\
55 \\
32\end{array}$ & $\begin{array}{r}m l . \\
70 \\
0 \\
186 \\
201 \\
107 \\
71 \\
0 \\
156 \\
0 \\
108 \\
0 \\
174 \\
00 \\
465 \\
0 \\
171 \\
0 \\
0 \\
134 \\
90 \\
174 \\
119 \\
221 \\
0\end{array}$ \\
\hline
\end{tabular}

Mean volume of abdominal gas $=116 \mathrm{ml}$.

$\mathrm{SD}=125 \mathrm{ml}$.

$\mathrm{SE}=18 \mathrm{ml}$.

\section{DISCUSSION}

Although the method for measurement of abdominal gas is apparently simple in principle, it is not easy for the subject because of the special and unnatural type of effort required to compress gas in the abdomen without at the same time compressing the gas in the lungs. In this series of experiments, 7 out of 67 subjects were unable to per- 
form the mechanical movements required by the test.

One of the theoretical questions in the method was whether change in gastric pressure is representative of change of pressure in the remainder of the gastro-intestinal tract. The finding that gas placed in the colon could be measured as accurately by this method as gas placed in the stomach seems to establish this point. In fact, colon gas seems to be measured more accurately than stomach gas as a comparison of the scatter diagrams will show. This is probably because large volumes of gas placed in the stomach are difficult for the subject to retain. For large volumes, failure to reach temperature equilibrium during compression would lead to underestimation of volumes. In a scatter diagram of stomach gas, 12 values are above the theoretical line and 24 are below it. Probably small volumes of gas escaped from the stomach during the experiments. Colonic gas was readily retained and there was no question of loss of gas by expulsion in these experiments. Since the tissues of the body are already equilibrated with 80 per cent nitrogen, the volume of air dissolved in gastro-intestinal fluids or absorbed through the mucosa must have been small during the 30-minute period of the test.

The $\mathrm{Y}$ intercepts of the regression lines calculated from measured volumes versus added volumes seem to be reasonably accurate, and this limits the possible random error in the initial measurement of abdominal gas.

The finding of an average volume of 0.1 liter is surprising in view of the previous report of one liter (1). The difference in results may be because of a difference in procedure. The present study was done at resting lung volume, whereas the prior measurements were made at the end of a full expiration. It can be shown that immediately after expiration, the expired gas condenses and cools in the box over a period of several seconds. Furthermore, at the end of a full expiration there may be a tendency for compression of alveolar air during further voluntary expiratory efforts. By radiographic estimation, the initial volume of gas is compatible with the plethysmographic finding of 0.1 liter, and is not compatible with an initial volume of the same order of magnitude as the volume added and subsequently visu- alized by X-ray. Addition of a liter of gas caused a subjective sensation of colic, or cramping abdominal pain, which was relieved by expulsion of the gas. Indeed the total volume added was limited by discomfort of the subject.

It can be deduced from the findings that the normal volume of gas in the intestinal tract is small and of the order of 0.1 liter. The presence of a volume of one liter in either stomach or colon is accompanied in normal subjects by discomfort and distension which are relieved by expulsion of the gas. This finding is of interest in relation to decompression because if the volume of gas normally present in the abdomen were 1 liter then explosive decompression, during which the abdominal gas expands two or three times, would be expected to produce considerable discomfort and pain in most subjects with the possible production of more serious damage to the bowel. When 234 subjects were explosively decompressed from 8,000 to 25,000 feet in 1 second, during which time the wet gas volume increases 2.2 times (4), 15 per cent had some abdominal distension and only 3 per cent had abdominal pain. These results are in keeping with a small normal abdominal gas volume such as has been found in this study.

The volume of gas in the lungs and abdomen is of importance in measuring the specific gravity of the body. A volume of $200 \mathrm{ml}$. of air in the body will give an error of .003 unit in measurement of specific gravity (5). The volume of gas that has been found in this study to be normally present in the abdomen is of the same order as the error of measurement of residual volume and so may be neglected, but if a larger volume of gas is present then its measurement is necessary in order to obtain an accurate value for specific gravity.

A method for the measurement of abdominal gas should also be of value for the quantitative assessment of the volume of gas in the gastro-intestinal tract in patients with a variety of gastrointestinal disorders and in the evaluation of the action of carminatives and of gas absorbing agents.

\section{SUMMARY}

A physical method for determination of the volume of abdominal gas based on voluntary compres- 
sion of the abdomen is described. This method is capable of measuring volumes of gas in the stomach within $180 \mathrm{ml}$. Gases in the colon are measured with equal accuracy.

The average volume of gas in the abdomen in 13 normal subjects was $115 \mathrm{ml}$. and the average volume of gas in the abdomen of 47 patients with lung disease was $116 \mathrm{ml}$.

\section{ACKNOWLEDGMENT}

The authors gratefully acknowledge the advice of Dr. J. H. Comroe, Jr., and Dr. P. J. Hodes.

\section{REFERENCES}

1. Blair, H. A., Dern, R. J., and Bates, P. L., The measurement of volume of gas in the digestive tract. Am. J. Physiol., 1947, 149, 688.
2. DuBois, A. B., Botelho, S. Y., Bedell, G. N., Marshall, R., and Comroe, J. H., Jr., A rapid plethysmographic method for measuring thoracic gas volume: A comparison with a nitrogen washout method for measuring functional residual capacity in normal subjects. J. Clin. Invest., 1956, 35, 322.

3. DuBois, A. B., Botelho, S. Y., and Comroe, J. H., Jr., A new method for measuring airway resistance in man using a body plethysmograph: Values in normal subjects and in patients with respiratory disease. J. Clin. Invest., 1956, 35, 327.

4. Barron, C. I., and Cook, T. J., Explosive decompression in altitude training of civilian air crews. J. Aviation Med., 1955, 26, 46.

5. Behnke, A. R., Jr., Feen, B. G., and Welham, W. C., The specific gravity of healthy men. Body weight $\div$ volume as an index of obesity. J. A. M. A., 1942, 118, 495. 